\title{
NUDT15 variant and thiopurine-induced leukopenia in Hong Kong
}

\author{
Felix CK Wong ${ }^{1}$, MB, BS, MResMed, Alex WK Leung ${ }^{2}$, MB, ChB, FHKAM (Paediatrics), \\ Jeffrey SS Kwok ${ }^{1}$, FHKCPath, FHKAM (Pathology), Michael HM Chan ${ }^{1}$, FHKCPath, FHKAM (Pathology), \\ CK Li ${ }^{2}$, MD, FHKAM (Paediatrics), YP Yuen ${ }^{1 *}$, FHKCPath, FHKAM (Pathology)
}

Departments of ${ }^{1}$ Chemical Pathology and ${ }^{2}$ Paediatrics, Prince of Wales Hospital, The Chinese University of Hong Kong, Shatin, Hong Kong

*Corresponding author: lizyuenyp@cuhk.edu.hk

Hong Kong Med J 2016;22:185-7

DOI: $10.12809 / \mathrm{hkmj} 154783$

Thiopurines, including azathioprine and 6-mercaptopurine (6-MP), are widely used in the treatment of autoimmune diseases and cancers, as well as prevention of rejection in organ transplantation. Azathioprine is a pro-drug that is converted to 6-MP, and subsequently undergoes extensive metabolism to the formation of 6 -thioguanine nucleotides (6-TGNs). Such 6-TGNs exert their therapeutic effect by inducing apoptosis of $\mathrm{T}$ lymphocytes. ${ }^{1}$ Myelosuppression, manifesting as a reduction in one or more of the haematopoietic lineages (most commonly leukopenia), is a serious adverse drug reaction related to the excessive generation of 6TGNs. $^{2}$ Thiopurine S-methyltransferase (TPMT) diverts 6-MP from the formation of 6-TGNs by converting 6-MP into inactive metabolites. Thus, TPMT deficiency plays a causal role in the pathogenesis of thiopurine-induced leukopenia by shunting thiopurine metabolites towards the formation of excessive 6-TGNs. Genetic variants present in the TPMT gene result in TPMT deficiency and the trait is inherited in an autosomal co-dominant manner. $T P M T^{*} 1$ represents the wild-type allele with normal TPMT activity while $* 2$, $3 \mathrm{~A}$, ${ }^{*} 3 \mathrm{~B},{ }^{*} 3 \mathrm{C}$, and $* 8$ account for approximately $95 \%$ of all TPMT variants known to result in TPMT deficiency. ${ }^{3}$ With the conventional dose of thiopurines, individuals who have inherited two copies of the inactive TPMT allele (homozygous deficient) experience severe myelosuppression. A significant proportion (30\%$60 \%$ ) of individuals who have inherited one copy of the inactive TPMT allele (heterozygous deficient) develop moderate-to-severe myelosuppression. Those who carry two wild-type TPMT alleles have the least myelosuppression. Prospective TPMT genotyping has been recommended by the US Food and Drug Administration. ${ }^{4,5}$ In addition, guidelines on TPMT genotype-based dosage recommendations are currently available that include a reduced thiopurine starting dose or use of an alternative non-thiopurine treatment in individuals who carry defective TPMT allele(s). ${ }^{6,7}$

In Hong Kong, many patients are prescribed thiopurine without prospective TPMT genotyping, largely because of the low frequency of TPMT variants in the Asian, including Chinese, population. The predominant TPMT variant in the Asian population is $* 3 \mathrm{C}$ (all other variants being exceedingly rare), with an allele frequency of $2.3 \%$, in contrast to the higher allele frequency of TPMT variants in the Caucasian population $(5.3 \%$ for all TPMT variants detected in one study). ${ }^{8}$ Nevertheless, thiopurine-induced myelosuppression is more common in the Asian than Caucasian population. ${ }^{9-11}$ Prospective TPMT genotyping can only identify a minor proportion of Asian patients who are at risk of thiopurine-induced myelosuppression. Moreover, the majority of Asian patients who are referred for TPMT genotyping after the occurrence of myelosuppression (called retrospective TPMT genotyping) do not carry any defective TPMT variant both in published studies ${ }^{10,12,13}$ or in the experience of the authors' laboratory that has provided a TPMT genotyping service since 2013 (Table). There are clearly additional genetic and/or non-genetic factors that contribute to an increased risk of thiopurineinduced myelosuppression in Asians.

In 2014, the NM_018283.2:c.415C > T, p.Arg139Cys (R139C) variant in the NUDT15 gene (dbSNP ID: rs116855232) was found to have a strong association with thiopurine-induced leukopenia in a large retrospective cohort of Koreans prescribed thiopurines for Crohn's disease. ${ }^{14}$ Of those patients who carried one or two NUDT15 R139C variants, 89.4\% (59/66) developed leukopenia within the first 8 weeks of thiopurine therapy (defined as early leukopenia). In contrast, this risk allele was found in only $6.8 \%$ (43/632) of controls who did not develop leukopenia while on thiopurine therapy. Most strikingly, all patients (14/14) who were homozygous for the R139C variant developed early leukopenia. In addition, $25.6 \%(45 / 176)$ and $50 \%(88 / 176)$ of patients who were heterozygous for the $\mathrm{R} 139 \mathrm{C}$ variant developed early and late leukopenia (occurrence of leukopenia after 8 weeks), respectively. A gene-dose effect was also seen as the number of risk alleles 
TABLE. Summary of patients referred to our laboratory for TPMT genotyping. The ethnic origin of all patients listed is Chinese

\begin{tabular}{|c|c|c|c|c|c|c|c|c|}
\hline $\begin{array}{l}\text { Patient } \\
\text { No. }\end{array}$ & $\begin{array}{c}\text { Age at } \\
\text { onset } \\
\text { (years) }\end{array}$ & Gender & $\begin{array}{l}\text { Indication for thiopurine } \\
\text { treatment }\end{array}$ & $\begin{array}{l}\text { Drug and maximum } \\
\text { dosage }\end{array}$ & $\begin{array}{c}\text { Nadir } \\
\text { WCC } \\
\left(\times 10^{9} / L\right)\end{array}$ & $\begin{array}{c}\text { Nadir } \\
\text { ANC } \\
\left(\times 10^{9} / L\right)\end{array}$ & $\begin{array}{l}\text { TPMT } \\
\text { genotype }\end{array}$ & NUDT15 genotype \\
\hline 1 & 23 & $\mathrm{~F}$ & SLE with recurrent myocarditis & AZA $50 \mathrm{mg}$ daily & 0.9 & 0.0 & ${ }^{*} 1 /{ }^{*} 1^{a}$ & Homozygous R139C \\
\hline 2 & 41 & $\mathrm{~F}$ & $\begin{array}{l}\text { SLE and scleroderma, with } \\
\text { cerebral lupus }\end{array}$ & AZA 100 mg daily & 1.0 & 0.1 & $* 1 / * 1$ & Homozygous R139C \\
\hline 3 & 21 & $\mathrm{~F}$ & Polyarteritis nodosa & AZA $50 \mathrm{mg}$ daily & 0.9 & 0.1 & ${ }^{*} 1 /{ }^{*} 1$ & Homozygous R139C \\
\hline 4 & 54 & $\mathrm{~F}$ & Pemphigus vulgaris & AZA $50 \mathrm{mg}$ daily & 0.2 & 0.0 & ${ }^{*} 1 /{ }^{*} 1$ & Homozygous R139C \\
\hline 5 & 61 & $\mathrm{~F}$ & SLE and lupus nephritis & AZA 75 mg daily & 1.0 & 0.5 & $* 1 / * 1$ & Heterozygous R139C \\
\hline 6 & 6 & M & Acute lymphoblastic leukaemia & 6-MP $25 \mathrm{mg}$ once per week & 0.8 & 0.0 & ${ }^{\star} 1 /{ }^{*} 6$ & Heterozygous R139C \\
\hline 7 & 44 & $\mathrm{~F}$ & SLE and lupus nephritis & AZA 150 mg daily & 0.9 & 0.6 & $* 1 / * 1$ & Wild-type \\
\hline 8 & 61 & $M$ & $\begin{array}{l}\text { Henoch-Schönlein purpura with } \\
\text { diffuse pulmonary haemorrhage }\end{array}$ & AZA 75 mg daily & 0.3 & 0.1 & ${ }^{*} 3 C /{ }^{*} 3 C$ & Unknown ${ }^{b}$ \\
\hline
\end{tabular}

Abbreviations: $A N C=$ absolute neutrophil count; $A Z A=$ azathioprine; $F=$ female; $M=$ male; 6 -MP = 6-mercaptopurine; SLE = systemic lupus erythematosus; WCC = white cell count

a * $^{\prime}$ * $\mid$ represents the homozygous wild-type TPMT genotype

b The blood sample of this patient was discarded 2 years after TPMT genotyping, thus retrospective NUDT 5 genotyping could not be performed

increased, demonstrated by a lower thiopurine dose at which leukopenia occurred, a shorter time interval from the start of treatment till occurrence of leukopenia, and a higher grade of leukopenia. Overall, the presence of one or two of this risk allele had a sensitivity of $89.4 \%$ and specificity of $93.2 \%$ for early leukopenia. The association of NUDT15 R139C with thiopurine-induced leukopenia has subsequently been demonstrated in Japanese patients with inflammatory bowel disease ${ }^{15}$ and Taiwan Chinese patients with childhood acute lymphoblastic leukaemia (ALL). ${ }^{16}$ NUDT15 R139C is much more common than the TPMT*3C variant in the Asian population, with an allele frequency of $16 \%$ in Southern Han Chinese. ${ }^{17}$ Thus, NUDT15 $\mathrm{R} 139 \mathrm{C}$ testing is of greater diagnostic value than TPMT genotyping for prospective risk assessment of thiopurine-induced leukopenia in the local Chinese population. The exact role of NUDT15 R139C in thiopurine toxicity remains unclear. NUDT15 is a nudix hydrolase that degrades 8-oxo-dGTP and 8 -oxo-dGDP in vitro, suggesting that it prevents misincorporation of 8-oxo-2'-deoxyguanosine 5'-triphosphate (8-oxo-dGDP) into DNA in vivo., ${ }^{3,18}$ In-vitro studies showed that treatment with 6-MP resulted in a higher percentage of apoptosis and necrosis in cells transfected with the NUDT15 R139C construct compared with cells with the wildtype construct. ${ }^{14}$

We performed NUDT15 R139C testing by polymerase chain reaction and bidirectional Sanger sequencing on all patient samples received by our laboratory for TPMT genotyping from August 2013 to November 2015. All patients were originally referred for retrospective TPMT genotyping. We received no requests for prospective TPMT genotyping during this period of time. The clinical history and test results are summarised in the Table. NUDT15 R139C was identified in six (85.7\%) of the seven patients referred to our laboratory for TPMT genotyping in whom a specimen was available for testing, while TPMT variants (" 6 and " $3 \mathrm{C}$ detected in this patient cohort) were identified in two (25\%) of the eight patients. The TPMT* 6 variant is a rare variant with an allele frequency of $0.16 \%$ in the Chinese population. ${ }^{19}$ Of the six patients who were positive for the NUDT15 R139C, four were homozygous, one was heterozygous, and one patient was doubly heterozygous for NUDT15 R139C and TPMT*6. The identification of double heterozygosity is clinically relevant as one study showed that double heterozygotes required a substantially lower dose intensity of 6-MP in the treatment of childhood ALL compared with those with heterozygous genotype for only one of the two genes. ${ }^{20}$ Although limited by the small number of cases, our results demonstrate the relevance of NUDT15 R139C testing in local Chinese patients who develop thiopurine-induced leukopenia. In view of the close association of NUDT15 R139C with early leukopenia and the relatively high carrier rate of this variant in the local Chinese population, prospective NUDT15 R139C testing together with TPMT genotyping will likely become a necessary requirement for all patients in whom thiopurine therapy is indicated. Dose recommendations based on combined NUDT15/ TPMT genotyping results may be feasible as more clinical data accumulate.

\section{References}

1. Tiede I, Fritz G, Strand S, et al. CD28-dependent Rac1 activation is the molecular target of azathioprine in primary 
human CD4+ T lymphocytes. J Clin Invest 2003;111:113345.

2. Lennard L, Lilleyman JS. Variable mercaptopurine metabolism and treatment outcome in childhood lymphoblastic leukemia. J Clin Oncol 1989;7:1816-23.

3. Roberts RL, Barclay ML. Update on thiopurine pharmacogenetics in inflammatory bowel disease. Pharmacogenomics 2015;16:891-903.

4. Imuran (azathioprine). FDA drug labels. Available from: http://www.accessdata.fda.gov/drugsatfda_docs/ label/2011/016324s034s035lbl.pdf. Accessed 21 Dec 2015.

5. Purinethol (mercaptopurine) 50-mg scored tablets. FDA drug labels. Available from: http://www.accessdata.fda. gov/drugsatfda_docs/label/2011/009053s032lbl.pdf. Accessed 21 Dec 2015.

6. Relling MV, Gardner EE, Sandborn WJ, et al. Clinical Pharmacogenetics Implementation Consortium guidelines for thiopurine methyltransferase genotype and thiopurine dosing. Clin Pharmacol Ther 2011;89:387-91.

7. Relling MV, Gardner EE, Sandborn WJ, et al. Clinical pharmacogenetics implementation consortium guidelines for thiopurine methyltransferase genotype and thiopurine dosing: 2013 update. Clin Pharmacol Ther 2013;93:324-5.

8. Collie-Duguid ES, Pritchard SC, Powrie RH, et al. The frequency and distribution of thiopurine methyltransferase alleles in Caucasian and Asian populations. Pharmacogenetics 1999;9:37-42.

9. Kim JH, Cheon JH, Hong SS, et al. Influences of thiopurine methyltransferase genotype and activity on thiopurineinduced leukopenia in Korean patients with inflammatory bowel disease: a retrospective cohort study. J Clin Gastroenterol 2010;44:e242-8.

10. Takatsu N, Matsui T, Murakami Y, et al. Adverse reactions to azathioprine cannot be predicted by thiopurine Smethyltransferase genotype in Japanese patients with inflammatory bowel disease. J Gastroenterol Hepatol 2009;24:1258-64.

11. Lee HJ, Yang SK, Kim KJ, et al. The safety and efficacy of azathioprine and 6-mercaptopurine in the treatment of
Korean patients with Crohn's disease. Intest Res 2009;7:2231.

12. Zhu Q, Cao Q. Thiopurine methyltransferase gene polymorphisms and activity in Chinese patients with inflammatory bowel disease treated with azathioprine. Chin Med J (Engl) 2012;125:3665-70.

13. Cao Q, Zhu Q, Shang Y, Gao M, Si J. Thiopurine methyltransferase gene polymorphisms in Chinese patients with inflammatory bowel disease. Digestion 2009;79:58-63.

14. Yang SK, Hong M, Baek J, et al. A common missense variant in NUDT15 confers susceptibility to thiopurineinduced leukopenia. Nat Genet 2014;46:1017-20.

15. Tanaka Y, Kato M, Hasegawa D, et al. Susceptibility to 6-MP toxicity conferred by a NUDT15 variant in Japanese children with acute lymphoblastic leukaemia. $\mathrm{Br} \mathrm{J}$ Haematol 2015;171:109-15.

16. Liang DC, Yang CP, Liu HC, et al. NUDT15 gene polymorphism related to mercaptopurine intolerance in Taiwan Chinese children with acute lymphoblastic leukemia. Pharmacogenomics J 2015 Oct 27. Epub ahead of print.

17. 1000 Genomes. Homo sapiens-Population geneticsrs116855232 (SNP). Available from: http:// browser.1000genomes.org/Homo_sapiens/Variation/ Population? $\mathrm{db}=$ core $; \mathrm{r}=13: 48619355-48620355 ; \mathrm{v}=\mathrm{rs} 11$ $6855232 ; \mathrm{vdb}=$ variation $; \mathrm{vf}=28973268$. Accessed 8 Nov 2015.

18. Takagi Y, Setoyama D, Ito R, Kamiya H, Yamagata Y, Sekiguchi M. Human MTH3 (NUDT18) protein hydrolyzes oxidized forms of guanosine and deoxyguanosine diphosphates: comparison with MTH1 and MTH2. J Biol Chem 2012;287:21541-9.

19. Kham SK, Soh CK, Liu TC, et al. Thiopurine Smethyltransferase activity in three major Asian populations: a population-based study in Singapore. Eur J Clin Pharmacol 2008;64:373-9.

20. Yang JJ, Landier W, Yang W, et al. Inherited NUDT15 variant is a genetic determinant of mercaptopurine intolerance in children with acute lymphoblastic leukemia. J Clin Oncol 2015;33:1235-42. 